\title{
Effect of the Addition of Sitagliptin and Miglitol on Insulin-Treated Type 2 Diabetes
}

Miyako Kishimoto $\cdot$ Mitsuhiko Noda

To view enhanced content go to www.diabetestherapy-open.com

Received: August 17, 2012 / Published online: September 28, 2012

(c) The Author(s) 2012. This article is published with open access at Springerlink.com

\section{ABSTRACT}

Introduction: To examine the efficacy of sitagliptin and miglitol when added to ongoing insulin treatment in a patient with type 2 diabetes who had undergone partial gastrectomy.

Methods: Continuous glucose monitoring (CGM) was performed and either sitagliptin or miglitol, or both, were added to fixed-dose insulin therapy. Blood was drawn at 0, 30, 60, and $120 \mathrm{~min}$ after breakfast, and C-peptide,

M. Kishimoto $(\bowtie) \cdot$ M. Noda

Department of Diabetes and Metabolic Medicine, Center Hospital, and Diabetes and Metabolism Information Center, Diabetes Research Center, National Center for Global Health and Medicine, 1-21-1 Toyama, Shinjuku-ku, Tokyo 162-8655, Japan

e-mail: mkishimo@hosp.ncgm.go.jp

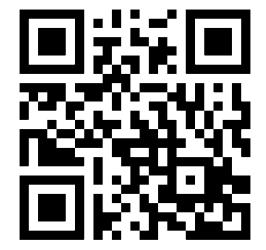

Enhanced content for this article is available on the journal web site: www.diabetestherapy-open.com glucagon, glucagon-like peptide (GLP)-1, and glucose-dependent insulinotropic peptide (GIP) were measured.

Results: CGM showed that compared to insulin alone, the addition of either sitagliptin or miglitol, or both, to insulin achieved better glucose control. Compared to insulin alone, early postprandial increments in plasma C-peptide levels and suppressed glucagon levels were observed when sitagliptin was added. Glucagon suppression was even more prominent when both sitagliptin and miglitol were added. Compared to insulin alone, GLP-1 levels were higher during the early postprandial stage when sitagliptin or miglitol was added and even higher when both were added. GIP levels decreased when sitagliptin or miglitol, or both, were added to insulin therapy.

Conclusion: The authors showed that the addition of sitagliptin or miglitol, or both, was effective in this insulin-treated patient with diabetes who had undergone gastrectomy.

Keywords: C-peptide; Continuous glucose monitoring; Glucagon-like peptide 1; Glucosedependent insulinotropic peptide; Insulin; Miglitol; Sitagliptin; Type 2 diabetes 


\section{INTRODUCTION}

Insulin injections are widely used as the most dependable treatment for diabetes. The effectiveness of insulin injections has been established in various clinical studies. However, an increase in insulin dosage to achieve better glycemic control is associated with an increased risk of hypoglycemia and weight gain [1]. Many patients with diabetes are being treated with insulin alone, but only a few patients are able to achieve optimal glycemic control with this treatment strategy. For these patients, combination therapy with insulin injection and oral medication is worth considering. Incretins [2-4], glucagon-like peptide 1 (GLP-1), and glucose-dependent insulinotropic polypeptide (GIP) are rapidly inactivated by the enzyme dipeptidyl peptidase 4 (DPP-4). DPP-4 inhibitors, such as sitagliptin [5], increase active GLP-1 and GIP levels by inhibiting DPP-4 enzymatic activity, and improve hyperglycemia in a glucose-dependent manner by increasing serum insulin and decreasing serum glucagon levels in patients with diabetes [6-10]. The safety and tolerability of sitagliptin has been demonstrated, with a low risk of hypoglycemia or weight gain [11]. Considering the different mechanisms and complementary effects of sitagliptin and insulin, a combination of these agents is a rational treatment option for insulin-treated patients [12]. Alpha-glucosidase inhibitors (alpha-GIs), such as miglitol, delay the absorption of digested carbohydrates from the small intestine and, thus, lower both postprandial glucose and insulin levels [13]. Alpha-GIs are considered to be effective for stabilizing glycemic levels in patients who have undergone gastric or esophageal surgery because alpha-GIs prevent reactive hypoglycemia due to late dumping syndrome
[14]. Therefore, the present study examined the efficacy of sitagliptin and miglitol when added to an ongoing insulin treatment in a patient with type 2 diabetes who had undergone partial gastrectomy. Efficacy was estimated with the use of a continuous glucose monitoring system (CGMS) [15-17], and by measuring hormones related to incretin and glucose metabolism.

\section{METHODS}

\section{Subject}

The patient was a 67-year-old Japanese man with a 15 -year history of type 2 diabetes. At the age of 55 years, the patient was diagnosed as having gastric cancer and underwent a distal partial gastrectomy with reconstruction via the Billroth I operation. The patient was being medicated with insulin lispro, which was injected at a dose of 10,12 , and 12 units just before breakfast, lunch, and dinner, respectively. The patient was also injecting 12 units of insulin glargine before going to bed. The patient had no diabetic complications, such as neuropathy, retinopathy, or nephropathy. The patient had concomitant hypertension, dyslipidemia, and nontuberculous mycobacterial infection, but all these comorbid diseases were well controlled with oral medication. The patient was admitted to the authors' hospital because of deteriorating diabetic control. The patient's height was $163.1 \mathrm{~cm}$, and at the time of admission, body weight was $66.9 \mathrm{~kg}$ (body mass index 25.2 $\mathrm{kg} / \mathrm{m}^{2}$ ). Hemoglobin A1c and glycoalbumin levels were $9.1 \%$ and $24.0 \%$, respectively. The urinary C-peptide level was $81.0 \mu \mathrm{g} / \mathrm{day}$. The patient provided written informed consent for participation in the study. 


\section{CGMS}

The patient was admitted to the diabetes ward of the authors' hospital and was equipped with a CGMS device $\left(\mathrm{CGMS}^{\circledR}-\mathrm{GOLD}^{\mathrm{TM}}\right.$; Medtronic MiniMed, Northridge, California, USA). The patient was monitored from 1 day before the study to the end of the 9-day study period. The CGMS soft sensor was changed at the appropriate times according to the manufacturer's instructions. Glucose levels measured using a self-monitoring blood glucose device (Nipro Stat Strip $\mathrm{XP}^{\circledR}$; Nipro, Osaka, Japan) were checked at least four times per day for calibration of the CGMS. The recorded data were analyzed using CGMS Solutions ${ }^{\circledR} \quad$ software (Medtronic MiniMed, Northridge, California, USA).

\section{Breakfast}

Breakfast with a similar number of calories each day was served throughout the study period. The total number of calories of a typical meal was $428 \mathrm{kcal}$, containing $73 \mathrm{~g}$ of carbohydrates, $14.2 \mathrm{~g}$ of protein, and $7.4 \mathrm{~g}$ of fat. The meal was ingested within 10-15 min.

\section{Sample Collection and Analysis}

On the first day of the study, after an overnight fast for $14 \mathrm{~h}$, an intravenous line was inserted into one forearm vein and flushed with sterile $0.9 \%$ $\mathrm{NaCl}$ solution for repeated blood sampling. Blood was drawn at $0,30,60$, and 120 min after breakfast for the measurement of serum C-peptide, plasma glucagon, active GLP-1, and total GIP levels. Blood samples were immediately cooled and centrifuged at $4{ }^{\circ} \mathrm{C}$, and plasma was stored at $-20^{\circ} \mathrm{C}$ until analysis. Blood samples for the determination of glucagon, active GLP-1, and total GIP levels were collected into $\mathrm{BD}^{\mathrm{TM}} \mathrm{P} 800$ tubes (Becton, Dickinson and Co., Franklin Lakes, New Jersey, USA) containing spray-dried potassium EDTA anticoagulant and a proprietary cocktail of protease, esterase, and DPP-4 inhibitors (Becton, Dickinson and Co.). Plasma samples for active GLP-1 measurements were subjected to solid-phase extraction to remove interference that affects immunoassays [18], and samples were analyzed using an enzyme-linked immunosorbent assay (ELISA) kit (Millipore Corp., Billerica, Massachusetts, USA). Plasma concentrations of amidated GLP-1 (7-36) and (7-37) were measured using an antibody that is highly specific for the N-terminus of GLP-1 and does not react with GLP-1 (9-36), GLP-2, or glucagon. The detection limit of the ELISA was $0.83 \mathrm{pmol} / \mathrm{L}$, with an intra-assay coefficient of variation $(\mathrm{CV})$ of $4.06-14.90 \%$ and an interassay CV of 11.1-13.2\%. The total GIP level was measured using a human GIP ELISA kit (Millipore Corp.). This kit has 100\% crossreactivity to human GIP (1-42) amide and GIP (3-42) amide, with a detection limit of $0.50 \mathrm{pmol} /$ $\mathrm{L}$, an intra-assay CV of $1.00-3.94 \%$, and an interassay CV of 4.99-10.10\%. Both active GLP-1 and total GIP levels were measured at Mitsubishi Chemical Medience Corp. (Tokyo, Japan). The serum C-peptide level was measured using an electrochemiluminescence immunoassay. Blood samples for glucagon detection were analyzed using a double-antibody radioimmunoassay at SRL, Inc. (Tokyo, Japan). The area under the curve (AUC) values for these hormones after meal ingestion were calculated using the trapezoidal rule.

\section{Medications}

Throughout the study period, insulin dosages were not changed. On the first and second days of the study (days 1 and 2), the patient used insulin alone. From days 3 to 6 , sitagliptin 
(50 mg, one tablet per day) was also taken, before breakfast, in addition to the insulin injections. On day 7, miglitol (50 mg, three tablets per day) was taken before meals, in addition to the insulin injections and sitagliptin. From day 8 to the end of the study, sitagliptin was discontinued, and the patient received only insulin injections and miglitol. Blood sampling was performed on days 2, 6, 7, and 9. The sampling methods and timing were identical for each blood sampling period.

\section{RESULTS}

Throughout the study period, continuous glucose monitoring (CGM) was completed without any problems and the patient
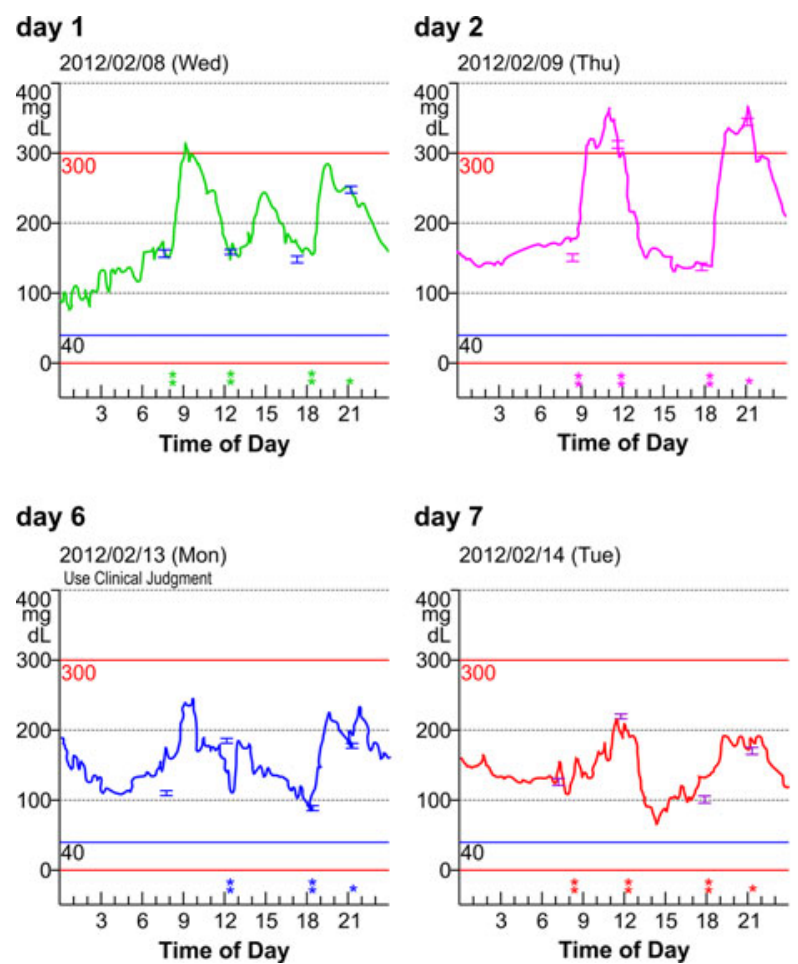

Fig. 1 CGM results during insulin therapy alone (days 1 and 2), insulin therapy plus sitagliptin (days 3, 4, and 6), insulin therapy plus sitagliptin and miglitol (day 7), and insulin therapy plus miglitol (days 8 and 9). The whole-day result of CGM on day 5 is not available, because the experienced no gastrointestinal symptoms associated with the study medications.

Figure 1 shows the escalations and fluctuations in glucose levels measured by CGM during treatment with insulin alone (days 1 and 2), insulin plus sitagliptin (days 3-6), insulin plus sitagliptin and miglitol (day 7), and insulin plus miglitol (days 8 and 9). The mean and SD values of CGM measurements for days 1 , $2,3,4,6,7,8$, and 9 were $185 \pm 58,210 \pm 75$, $154 \pm 44, \quad 157 \pm 53, \quad 158 \pm 36, \quad 144 \pm 31$, $137 \pm 30$, and $132 \pm 31 \mathrm{mg} / \mathrm{dL}$, respectively, reflecting the attenuation of glucose fluctuations when sitagliptin, miglitol, or both, were added to insulin therapy.

Time-dependent changes in C-peptide, glucagon, active GLP-1 and total GIP levels, day 3

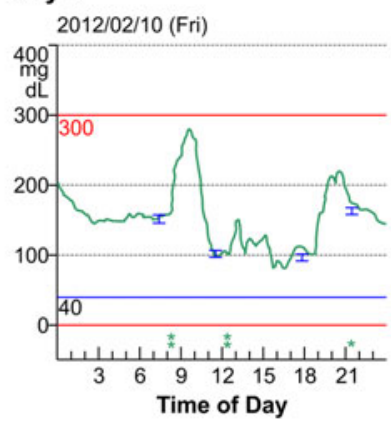

day 8

2012/02/15 (Wed)

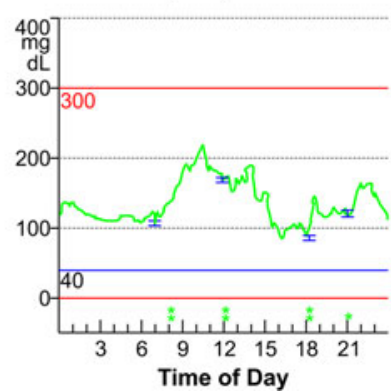

day 4

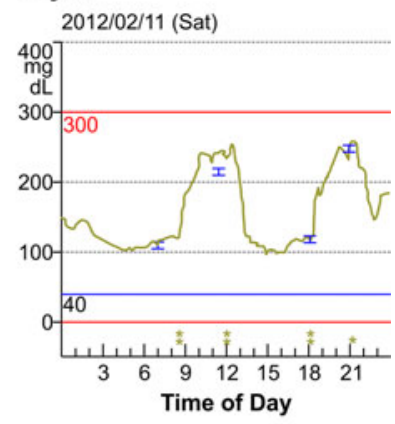

day 9

2012/02/16 (Thu)

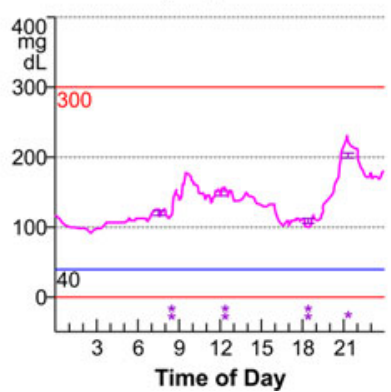

CGMS soft sensor changed. Double asterisk indicates times of meals (this sign for dinner for day 3 , and breakfast for day 6 are missing). Single asterisk indicates times of bedtime calibration. CGM continuous glucose monitoring, CGMS continuous glucose monitoring system 
and the AUC values of these hormones up to $2 \mathrm{~h}$ after meal ingestion are summarized in Table 1 and Fig. 2. Compared to insulin alone, remarkable early postprandial increments in plasma C-peptide levels were observed when sitagliptin was added to insulin therapy, whereas no remarkable changes in postprandial increments in plasma C-peptide levels were observed when insulin was administered in combination with sitagliptin and miglitol or when insulin was administered with miglitol only (Fig. 2a). Compared to insulin alone, the addition of sitagliptin to insulin therapy suppressed glucagon levels for at least $2 \mathrm{~h}$ after meal ingestion. This tendency was even more prominent when miglitol was coadministered with sitagliptin and insulin; however, the administration of miglitol in combination with insulin had no observable effect on glucagon levels during the early postprandial phase (Fig. 2b). Compared with insulin alone, the addition of sitagliptin or miglitol to insulin therapy increased GLP-1 levels at least $30 \mathrm{~min}$ after meal ingestion. When both sitagliptin and miglitol were added to insulin therapy, remarkable incremental increases in GLP-1 levels were observed. GLP-1 fluctuation in response to sitagliptin or miglitol alone was transient, as opposed to the sustained increase observed when both drugs were combined with insulin (Fig. 2c). In contrast to the GLP-1 results, GIP levels decreased when sitagliptin or miglitol was added to insulin therapy. This tendency was particularly prominent when both sitagliptin and miglitol were added to insulin therapy (Fig. 2d).

\section{DISCUSSION}

The results of the present study in a Japanese patient with type 2 diabetes show that the administration of sitagliptin in addition to insulin therapy has beneficial effects on stabilizing the fluctuating glucose levels. The administration of miglitol in addition to insulin therapy and the coadministration of sitagliptin and miglitol also had beneficial effects in lowering glycemic levels in this patient. These effects were demonstrated precisely by the mean \pm SD values and calculated AUC values of the glucose levels monitored by CGMS. The authors have previously shown that the

Table 1 AUC values during the 2-h meal test

\begin{tabular}{|c|c|c|c|c|}
\hline & Insulin alone & Insulin + sitagliptin & Insulin + sitagliptin + miglitol & Insulin + miglitol \\
\hline $\begin{array}{l}\text { Glucose (CGM) AUC } \\
(\mathrm{mg} / \mathrm{dL} \times 2 \mathrm{~h})\end{array}$ & 35,345 & 26,265 & 17,588 & 18,528 \\
\hline $\begin{array}{l}\text { C-peptide AUC } \\
(\mathrm{nmol} / \mathrm{L} \times 2 \mathrm{~h})\end{array}$ & 79.4 & 105.2 & 62.1 & 62.9 \\
\hline $\begin{array}{c}\text { Glucagon AUC } \\
(\mathrm{ng} / \mathrm{L} \times 2 \mathrm{~h})\end{array}$ & 7,725 & 6,210 & 5,235 & 7,335 \\
\hline $\begin{array}{l}\text { Active GLP-1 AUC } \\
(\mathrm{pmol} / \mathrm{L} \times 2 \mathrm{~h})\end{array}$ & 266.7 & 355.4 & 789.5 & 392.2 \\
\hline $\begin{array}{l}\text { Total GIP AUC } \\
(\mathrm{pmol} / \mathrm{L} \times 2 \mathrm{~h})\end{array}$ & 9,270 & 5,532 & 1,993 & 4,210 \\
\hline
\end{tabular}

$A U C$ area under the curve, $C G M$ continuous glucose monitoring, GIP glucose-dependent insulinotropic peptide, GLP-1 glucagon-like peptide 1 


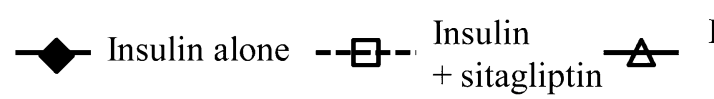

$\begin{array}{ll}\text { Insulin + sitagliptin } & \cdots \cdot \times \cdots \cdot . \cdot \text { Insulin } \\ + \text { miglitol } & + \text { miglitol }\end{array}$
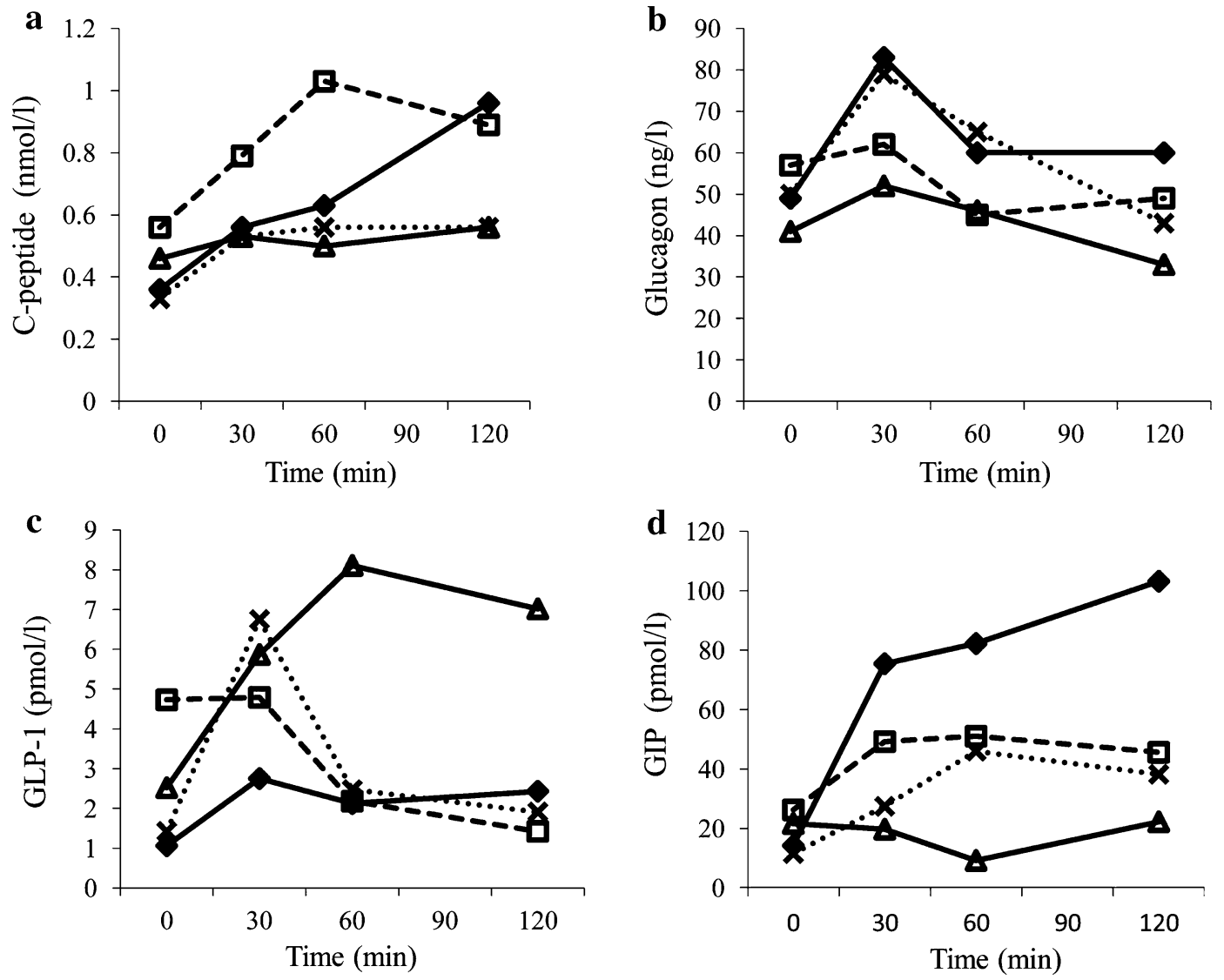

Fig. 2 Time course of plasma C-peptide (a), glucagon (b), active GLP-1 (c), and GIP (d) levels before and after food intake in the patient. Thick line with filled diamond insulin alone, dashed line with square insulin + sitagliptin, thin line

with triangle insulin + sitagliptin + miglitol, dotted line with times symbol insulin + miglitol. GIP glucosedependent insulinotropic peptide, GLP-1 glucagon-like peptide-1

combination of sitagliptin and miglitol was effective for reducing glucose fluctuations and stabilizing postprandial blood glucose levels in patients with type 2 diabetes receiving oral medication [19]. In the present study, the authors have demonstrated that both single administration and coadministration of these two drugs was also effective in an insulintreated patient.

Compared to insulin therapy alone, the addition of sitagliptin to insulin therapy was associated with higher C-peptide and GLP-1 levels, and lower glucagon and GIP levels,

indicating that sitagliptin stimulated GLP-1 and endogenous insulin secretion, and suppressed glucagon and GIP levels. When miglitol was added to insulin therapy, GLP-1 levels during the early postprandial phase were higher than those seen with insulin therapy alone; however, unlike the case when sitagliptin was added, glucagon levels were not suppressed. However, GIP levels were suppressed to a level similar to that when sitagliptin was added to insulin therapy. These results are consistent with previous reports, which showed that miglitol enhances and prolongs GLP-1 release 
and suppresses plasma GIP secretion [20-22]. The coadministration of sitagliptin and miglitol with insulin therapy was associated with a significant increase in GLP-1 secretion. The authors theoretically expected a postprandial increment in C-peptide levels as a result of the increased GLP-1 secretion; however, compared to insulin therapy alone, no remarkable changes in C-peptide levels were seen with sitagliptin and miglitol coadministration, which may be partly explained by the induced decrease in blood glucose levels. In contrast, the coadministration of sitagliptin and miglitol with insulin therapy was associated with significantly suppressed glucagon and GIP levels, indicating that the combination of these drugs acted synergistically to suppress glucose increments.

Vilsbøll et al. [12] reported in a 24-week study that the addition of sitagliptin to ongoing insulin therapy resulted in significant improvements in glycemic control by improving beta-cell responsiveness relative to a placebo. The authors concluded that their findings were consistent with the mechanism of action of sitagliptin [6], and that in patients with more advanced disease and beta-cell failure, sitagliptin may still favorably impact glucose-dependent insulin secretion. In another report, Ahren et al. [23] demonstrated that vildagliptin, another DPP-4 inhibitor, enhanced alpha-cell responsiveness to both the suppressive effects of hyperglycemia and the stimulatory effects of hypoglycemia, concluding that these effects probably contributed to the improvement in glycemic control. Those reports support the authors' findings that the addition of a DPP-4 inhibitor to insulin therapy has beneficial effects on stabilizing glycemic control by stimulating endogenous insulin secretion and suppressing glucagon secretion. It is encouraging that these favorable effects were evident in a patient with a long history of diabetes, such as the present patient. In addition, previous reports have demonstrated that in type 1 diabetes, exogenous GLP-1 lowered peak postprandial glucose levels regardless of residual beta-cell function [24], lowered fasting glycemia mainly by reducing glucose concentration [25], and presumably delayed gastric emptying and could normalize glycemic excursion after a meal when given in combination with insulin [26]. Vildagliptin has also been reported to be beneficial for decreasing postmeal glucagon excursion in insulinopenic patients with type 1 diabetes; this effect was not secondary to a change in endogenous insulin secretion [27]. These reports encourage the use of incretin-related agents in insulin-treated patients with type 1 or type 2 diabetes.

In addition to sitagliptin, the addition of miglitol to insulin therapy had favorable effects on stabilizing glycemic control, in a patient who had undergone gastrectomy, such as the present patient [14]. When both sitagliptin and miglitol were added to insulin therapy, the present patient experienced hypoglycemia that the patient was not completely aware of, but was revealed later by the CGM results. Therefore, caution should be exercised when these combinations are used and a reduction in the insulin dose should be considered. In other words, by adding these drugs to insulin therapy, the authors are able to reduce the insulin dose and are thus able to reduce the risk of undesired side effects of insulin treatments, such as severe hypoglycemia and increasing body weight $[28,29]$.

\section{CONCLUSION}

In conclusion, with the use of CGMS, the authors have shown that the addition of a DPP-4 inhibitor, such as sitagliptin, was effective in reducing glucose fluctuations and stabilizing postprandial blood glucose levels in 
an insulin-treated patient. The addition of an alpha-GI, such as miglitol, to insulin therapy was also effective in this patient with diabetes who had undergone gastrectomy. Because the present patient was a thin man with very low C-peptide levels and the dynamics of glucose absorption were greatly influenced by gastric resection, the authors are unable to apply the present findings to a general population of individuals with type 2 diabetes. To verify the effectiveness of sitagliptin in insulin-treated patients, further studies in a larger number of patients are needed, including patients with other insulin regimens, for instance, once-daily injection of long-acting insulin or mixed insulin agents two or three times daily.

\section{ACKNOWLEDGMENTS}

This work was supported by a grant from the Joint Research Association for Japanese Diabetes. Dr. Kishimoto is the guarantor for this article, and takes responsibility for the integrity of the work as a whole.

Conflict of interest. The authors declare that they have no conflicts of interest.

Open Access. This article is distributed under the terms of the Creative Commons Attribution Noncommercial License which permits any noncommercial use, distribution, and reproduction in any medium, provided the original author(s) and the source are credited.

\section{REFERENCES}

1. Mäkimattila S, Nikkilä K, Yki-Järvinen H. Causes of weight gain during insulin therapy with and without metformin in patients with type II diabetes mellitus. Diabetologia. 1999;42:406-12.
2. Drucker DJ. The role of gut hormones in glucose homeostasis. J Clin Invest. 2007;117:24-32.

3. Meier JJ, Nauck MA. Incretins and the development of type 2 diabetes. Curr Diab Rep. 2006;6:194-201.

4. Holst JJ. The physiology of glucagon-like peptide 1 . Physiol Rev. 2007;87:1409-39.

5. Merck Sharpe \& Dohme. Januvia ${ }^{\circledR}$ (sitagliptin) tablets. Highlights of prescribing information. http://www.merck.com/product/usa/pi_circulars/j/ januvia/januvia_pi.pdf. Accessed 7 Sept 2012.

6. Herman GA, Bergman A, Stevens C, et al. Effect of single oral doses of sitagliptin, a dipeptidyl peptidase-4 inhibitor, on incretin and plasma glucose levels after an oral glucose tolerance test in patients with type 2 diabetes. J Clin Endocrinol Metab. 2006;91:4612-9.

7. Karasik A, Aschner P, Katzeff H, Davies MJ, Stein PP. Sitagliptin, a DPP-4 inhibitor for the treatment of patients with type 2 diabetes: a review of recent clinical trials. Curr Med Res Opin. 2008;24:489-96.

8. Xu L, Dalla Man C, Charbonnel B, et al. Effect of sitagliptin, a dipeptidyl peptidase- 4 inhibitor, on beta-cell function in patients with type 2 diabetes: a model-based approach. Diabetes Obes Metab. 2008;10:1212-20.

9. Brazg R, Xu L, Dalla Man C, Cobelli C, Thomas K, Stein PP. Effect of adding sitagliptin, a dipeptidyl peptidase-4 inhibitor, to metformin on 24-h glycaemic control and beta-cell function in patients with type 2 diabetes. Diabetes Obes Metab. 2007;9:186-93.

10. Drucker DJ, Nauck MA. The incretin system: glucagon-like peptide-1 receptor agonists and dipeptidyl peptidase- 4 inhibitors in type 2 diabetes. Lancet. 2006;368:1696-705.

11. Williams-Herman D, Round E, Swern AS, et al. Safety and tolerability of sitagliptin in patients with type 2 diabetes: a pooled analysis. BMC Endocr Disord. 2008;8:14.

12. Vilsbøll T, Rosenstock J, Yki-Järvinen $\mathrm{H}$, et al. Efficacy and safety of sitagliptin when added to insulin therapy in patients with type 2 diabetes. Diabetes Obes Metab. 2010;12:167-77.

13. Scheen AJ. Is there a role for alpha-glucosidase inhibitors in the prevention of type 2 diabetes mellitus? Drugs. 2003;63:933-51.

14. Imhof A, Schneemann M, Schaffner A, Brändle M. Reactive hypoglycaemia due to late dumping syndrome: successful treatment with acarbose. Swiss Med Wkly. 2001;131:81-3. 
15. Gross TM, Bode BW, Einhorn D, et al. Performance evaluation of the MiniMed continuous glucose monitoring system during patient home use. Diabetes Technol Ther. 2000;2:49-56.

16. Kaufman FR, Gibson LC, Halvorson M, Carpenter S, Fisher LK, Pitukcheewanont P. A pilot study of glucose measurements using the glucose sensor. Diabetes Care. 2002;25:1185-91.

17. Sachedina N, Pickup JC. Performance assessment of the Medtronic-MiniMed continuous glucose monitoring system and its use for measurement of glycaemic control in type 1 diabetic subjects. Diabet Med. 2003;20:1012-5.

18. Yabe D, Watanabe K, Sugawara K, et al. Comparison of incretin immunoassays with or without plasma extraction: incretin secretion in Japanese patients with type 2 diabetes. J Diabetes Invest. 2011;3:70-9.

19. Kishimoto M, Noda M. A pilot study of the efficacy of miglitol and sitagliptin for type 2 diabetes with a continuous glucose monitoring system and incretinrelated markers. Cardiovasc Diabetol. 2011;10:115.

20. Narita T, Katsuura Y, Sato T, et al. Miglitol induces prolonged and enhanced glucagon-like peptide-1 and reduced gastric inhibitory polypeptide responses after ingestion of a mixed meal in Japanese type 2 diabetic patients. Diabet Med. 2009;26:187-8.

21. Lee A, Patrick P, Wishart J, Horowitz M, Morley JE. The effects of miglitol on glucagon-like peptide-1 secretion and appetite sensations in obese type 2 diabetics. Diabetes Obes Metab. 2002;4:329-35.

22. Narita $T$, Yokoyama $H$, Yamashita $R$, et al. Comparison of the effects of 12-week administration of miglitol and voglibose on the responses of plasma incretins after a mixed meal in Japanese type 2 diabetic patients. Diabetes Obes Metab. 2012;14:283-7.

23. Ahren B, Schweizer A, Dejager S, et al. Vildagliptin enhances islet responsiveness to both hyper- and hypoglycemia in patients with type 2 diabetes. J Clin Endocrinol Metab. 2009;94:1236-43.

24. Kielgast U, Holst JJ, Madsbad S. Antidiabetic actions of endogenous and exogenous GLP-1 in type 1 diabetic patients with and without residual $\beta$-cell function. Diabetes. 2011;60:1599-607.

25. Creutsfeldt WOC, Kleine N, Willms B, Ørskov C, Holst JJ, Nauck MA. Glucagonostatic actions and reduction of fasting hyperglycemia by exogenous glucagon-like peptide 1 (7-36) amide in type 1 diabetic patients. Diabetes Care. 1996;19:580-6.

26. Duppe J, Behme MT, Hramiak IM, McDonald TJ. Subcutaneous glucagon-like peptide 1 combine with insulin normalizes postcibal glycemic excursions in IDDM. Diabetes Care. 1997;20:381-4.

27. Foley JE, Ligueros-Saylan M, He Y-L, et al. Effect of vildagliptin on glucagon concentration during meals in patients with type 1 diabetes. Horm Metab Res. 2008;40:727-30.

28. Rosenstock J, Rendell M, Gross J, Fleck P, Wilson C, Mekki Q. Alogliptin added to insulin therapy in patients with type 2 diabetes reduces $\mathrm{HbA}_{1 \mathrm{c}}$ without increasing weight gain or hypoglycemia. Diabetes. 2008;57(Suppl. 1):A132-3.

29. Fonseca V, Schweizer A, Albrecht D, Baron MA, Chang I, Dejager S. Addition of vildagliptin to insulin improves glycaemic control in type 2 diabetes. Diabetologia. 2007;50:1148-55. 